Impact of extended contact co-firing on multicrystalline silicon solar cell parameters

Ana Peral, Amir Dastgheib-Shirazi, Vanesa Fano, Juan Carlos Jimeno, Giso Hahn, and Carlos del Cañizo

IEEE Journal of Photovoltaics

(c) 2016 IEEE. Personal use of this material is permitted. Permission from IEEE must be obtained for all other users, including reprinting/ republishing this material for advertising or promotional purposes, creating new collective works for resale or redistribution to servers or lists, or reuse of any copyrighted components of this work in other works 


\title{
Impact of extended contact co-firing on multicrystalline silicon solar cell parameters
}

\author{
Ana Peral, Amir Dastgheib-Shirazi, Vanesa Fano, Juan Carlos Jimeno, Giso Hahn, and Carlos del Cañizo
}

\begin{abstract}
During the temperature spike of the contact co-firing step in a solar cell process, it has been shown that the concentration of lifetime-killer dissolved metallic impurities increases, while adding an annealing after the spike getters most of the dissolved impurities towards the phosphorus emitter, where they are less detrimental. The contact co-firing temperature profile including the after-spike annealing has been called extended contact co-firing, and it has also been proposed as a means to decrease the emitter saturation current density of highly doped emitters, benefiting thus a wide range of materials in terms of detrimental impurity content. The aim of the present work is to determine the effect of performing this additional annealing on contact quality and solar cell performance, looking for an optimal temperature profile for reduction of bulk and emitter recombination without affecting contact quality. It presents the effect of the extended co-firing step on fill factor, series resistance and contact resistance of solar cells manufactured with different extended co-firing temperature profiles. Fill factor decreases when extended co-firing is performed. Series resistance and contact resistance increase during annealing, more dramatically when the temperature peak is decreased. Scanning Electron Microscopy (SEM) images show silver crystallites in contact with silver bulk before the annealing that allow a direct current path, and silver crystallites totally surrounded by glass layer $(>100 \mathrm{~nm}-$ thick) after annealing. Glass layer redistribution and thickening at low temperatures at the semiconductor-metal interface can be related to the series resistance increase. Degradation of series resistance during the temperature spike, when it is below the optimum one, can be also attributed to an incomplete silicon nitride etching and silver crystallite formation. To make full use of the beneficial effects of annealing, screen-printing metallic paste development supporting lower temperatures without thick glass layer growth is needed.
\end{abstract}

Index Terms-Co-firing step, Low Thermal Annealing, extended gettering, contact formation.

\section{INTRODUCTION}

$\mathbf{C}$ ONTACT formation is the last step of conventional industrial silicon solar cell production. The state-of-theart technology consists of printing metal-based pastes on top of silicon nitride layer for the front side and on silicon for the bottom side, followed by a fast inline co-firing at high temperature. This co-firing temperature profile requires a drying step with temperatures below $400{ }^{\circ} \mathrm{C}$ for burning out the organic binders, a step with temperatures between $475{ }^{\circ} \mathrm{C}$

A. Peral and C. del Cañizo are with the Universidad Politecnica de Madrid, Instituto de Energa Solar 28040 Madrid, Spain (e-mail: ana.peral@iesdef.upm.es; carlos.canizo@ies.upm.es)

A. Dastgheib-Shirazi and G. Hahn are with the University of Konstanz, Department of Physics 78457 Konstanz, Germany (e-mail: amir.dastgheibshirazi@uni-konstanz.de; giso.hahn@uni-konstanz.de)

V. Fano and J. C. Jimeno are with the Universidad del Pais Vasco, Instituto de Tecnologa Microelectrnica 48013 Bilbao, Spain (e-mail: vanesa.fano@ehu.eus; jc.jimeno@ehu.es) and $600{ }^{\circ} \mathrm{C}$ that melts the glass frit and sinters the silver, and a short spike with a temperature between $600{ }^{\circ} \mathrm{C}$ and $900{ }^{\circ} \mathrm{C}$ that etches the dielectric silicon nitride antireflection coating and facilitates the formation of silver crystallites on the silicon surface [1]-[4].

In addition, it has been experimentally demonstrated in previous works that during the contact co-firing step the concentration of dissolved iron in the wafer bulk is increased, decreasing bulk lifetime. Predictive Impurity-to-Efficiency simulations [5], [6] show a relative increase of dissolved iron during the standard co-firing step between $200 \%$ and $1000 \%$ for materials with high total contamination concentration (with initial total $\mathrm{Fe}$ concentrations between $10^{15}$ and $10^{16}$ $\mathrm{cm}^{-3}$ and iron precipitate radii between 15 and $50 \mathrm{~nm}$ ). This increase can be attributed to the dissolution of iron precipitates [5]-[7], and also to the re-injection of iron from the emitter into the bulk [8], [9]. However, adequate defect engineering tools can compensate completely or partly this increase thanks to an external gettering into the phosphorus and aluminum layers during the temperature plateau. A short annealing step $(5 \mathrm{~min})$ after the standard co-firing has been calculated to decrease dissolved iron concentration more than $100 \%$ (comparing with results after standard recipe) for most part of conventional commercial materials, including the highly contaminated ones. Due to the fact that the concept is somewhat similar to what is called extended gettering [10]-[12], it was called extended co-firing.

It must also be noted that an additional benefit of a low temperature anneal comes from a reduction in the emitter saturation current density as compared to a process without annealing, as has been shown recently in [13].

This paper deals with the consequences of an extended co-firing step on solar cell performance. As a change in firing conditions might have consequences for contact formation in general and contact resistance in particular, we investigate the behavior of these parameters on solar cell level and trace them back to their microscopic origin.

\section{EXTENDED CO-FIRING ON CONTAMINATED MC-SI}

This section presents an example of how the co-firing temperature profile impacts bulk lifetime of multicrystalline material, but other factors should be taken into account for that to be reflected in solar cell performance. 

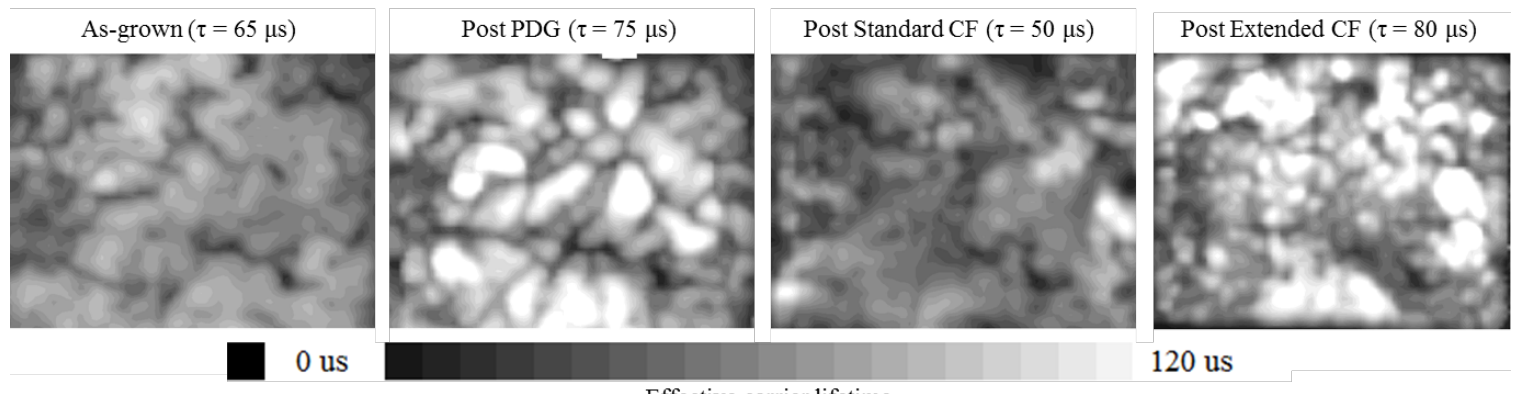

120 us

Effective carrier lifetime

Fig. 1. Effective carrier lifetime mapping $\mu \mathrm{W}$-PCD of wafers as-grown, post PDG, post standard co-firing (CF) and post extended CF. Lifetime is scaled from $0 \mu$ s to $120 \mu$ s. Mean lifetime is indicated above the figures.

Fig. 1 presents the effect of thermal steps during the solar cell fabrication process on bulk lifetime. Neighbouring p-type $1.7 \Omega \cdot \mathrm{cm}$ multicrystalline (mc) Si wafers of low quality in terms of impurity content are used, with an area of $3 \times 4$ $\mathrm{cm}^{2}$. They have received a $\mathrm{POCl}_{3}$ diffusion obtaining a sheet resistance of $35 \Omega / \square$, HF-dip for phosphorus-silicate glass removal, silicon nitride $\left(\mathrm{SiN}_{\mathrm{x}}\right)$ Plasma-Enhanced Chemical Vapor Deposition (PECVD) on the front surface, front Ag-paste and rear Al-paste screen-printing, and standard or extended co-firing (with a 100 seconds annealing) in an in-line belt furnace, using similar recipes as the temperature profiles presented in Ref. [6]. Reference samples for lifetime measurements follow the process, and after each step surface layers are etched, chemical cleaning is performed and fresh $\mathrm{SiN}_{\mathrm{x}}$ is deposited on both surfaces to evaluate the bulk quality. Spatially resolved effective carrier lifetime measurements are made using a Microwave-detected Photoconductance Decay ( $\mu$-PCD) setup

Arithmetic mean effective lifetime $\left(\tau_{\mathrm{eff}}\right)$ of the as-grown wafer is $65 \mu \mathrm{s}$. After emitter diffusion (post-PDG sample), $\tau_{\text {eff }}$ increases above the initial value $(75 \mu \mathrm{s})$. Experiments confirm that the short $925{ }^{\circ} \mathrm{C}$ set temperature spike of $10 \mathrm{~s}$ during standard co-firing causes a decrease of post-processed $\tau_{\text {eff }}(50 \mu \mathrm{s})$. However, after using extended co-firing instead of the standard one, mean lifetime measured is well above the value post-PDG $(80 \mu \mathrm{s})$ thanks to external gettering. This effect can be specially appreciated inside the grains in Fig. 1. Similar results were found studying the phosphorus gettering effect during the co-firing step without using screen-printed metal pastes [5], [6].

Open circuit voltage $\left(\mathrm{V}_{\text {oc }}\right)$ measurements of the final cells corresponding to the materials shown in Fig. 1 achieved values of $590 \mathrm{mV}$ for a sample with standard co-firing and $595 \mathrm{mV}$ for a sample with extended co-firing. Both $\mathrm{V}_{\mathrm{oc}}$ values are limited in this experiment by the low quality $\mathrm{mc}$ material and the highly doped emitter that produces high recombination. The $35 \Omega / \square$ emitter was chosen so as to maximize the impurity gettering effect during the annealing and to obtain a better contact quality. However, this Voc enhancement is not reflected in efficiency, which is measured to be similar for cells with the extended co-firing and with the standard one. The hypothesis is that in this experiment the efficiency after extended co-firing was limited by a poor contact because temperature profile was optimized for gettering effect but not for contacting. Besides the dissolution and gettering of lifetime-killing impurities, the cofiring step must also ensure a low contact resistance, etching uniformly the dielectric and forming $\mathrm{Ag}$ crystallites to allow the flow of photogenerated carriers to the contact; in addition, it must avoid p-n-junction shunting by over-firing [14].

The objective of the present work is to study the effect of an annealing performed after the co-firing temperature spike on contact quality and on cell performance, and to discuss the possibility of optimizing the temperature profile to include the benefits of a reduction in bulk and emitter recombination.

This aim is approached through the fabrication of simplified $\mathrm{Si}$ solar cells using an industrial belt furnace for implementing the extended co-firing of the contacts, and characterizing the contact properties for a set of annealing profiles.

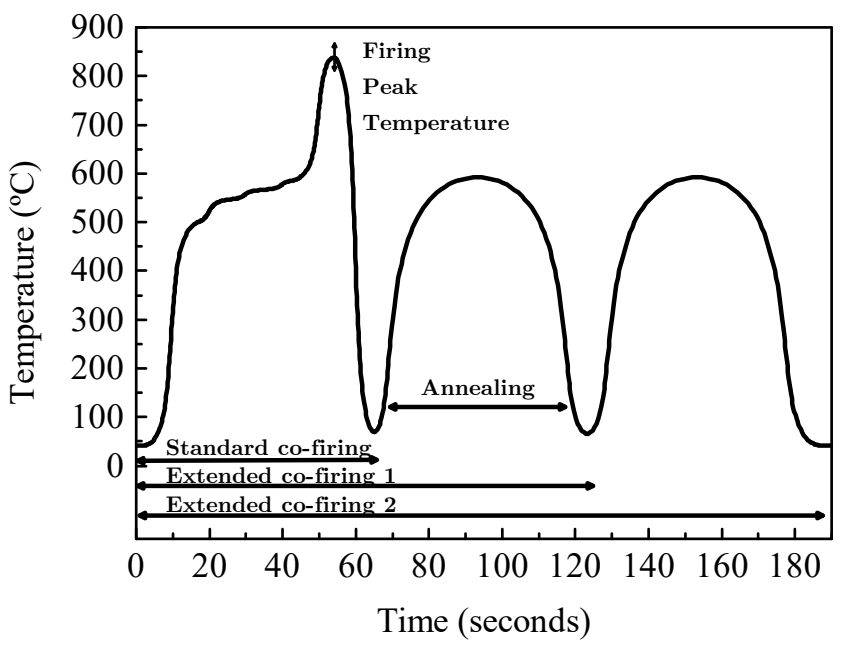

Fig. 2. Set temperature profiles of standard co-firing and variations of extended co-firing 1 and 2. 
TABLE I

SOLAR CELL PERFORMANCE MEASURED AT STANDARD CONDITIONS FOR THREE REFERENCE CELLS, EACH ONE WITH CO-FIRING PROFILE CORRESPONDING TO FIG. 2 . THE FITTED VALUES FOR SHUNT AND SERIES RESISTANCES ARE ALSO SHOWN.

\begin{tabular}{ccccccc}
\hline \hline Temperature profile & $\begin{array}{c}\eta \\
(\%)\end{array}$ & $\begin{array}{c}\mathrm{FF} \\
(\%)\end{array}$ & $\begin{array}{c}V_{\mathrm{oc}} \\
(\mathrm{mV})\end{array}$ & $\begin{array}{c}J_{\text {sc }} \\
\left(\mathrm{mA} / \mathrm{cm}^{2}\right)\end{array}$ & $\begin{array}{c}R_{\text {shunt }} \\
\left(\Omega \cdot \mathrm{cm}^{2}\right)\end{array}$ & $\begin{array}{c}R_{\text {series }} \\
\left(\Omega \cdot \mathrm{cm}^{2}\right)\end{array}$ \\
\hline \hline Standard co-firing & 15.2 & 79.4 & 615 & 31.1 & 7283 & 0.4 \\
Extended co-firing 1 & 14.8 & 78.7 & 613 & 30.8 & 11000 & 0.6 \\
Extended co-firing 2 & 14.2 & 75.4 & 612 & 30.8 & 8330 & 0.9 \\
\hline \hline
\end{tabular}

\section{Material AND MethodS}

Solar cells are processed on $156 \times 156 \mathrm{~mm}^{2}, 2 \Omega \cdot \mathrm{cm}$ resistivity, $200 \mu \mathrm{m}$-thick, p-type boron doped high quality mc$\mathrm{Si}$ wafers. After a standard chemical cleaning procedure, a $\mathrm{POCl}_{3}$ diffusion process is carried out obtaining a $30 \Omega / \square$ sheet-resistance emitter. Then, the front side of the wafers is coated with PECVD silicon nitride. A collection grid is screen-printed with commercial Ag paste on the front side and Al paste is screen-printed on the rear side. Finally, contact is formed by co-firing the wafers in an infrared belt furnace in air ambient.

Note that selected material -high quality mc-Si wafers- has been chosen for a more straightforward characterization of the contacting issues associated with the extended co-firing step although due to its low content of detrimental impurities it is not the most appropriate to see the bulk recombination decrease using the extended co-firing. Also note that mc-Si cells are not textured to reduce potential variations due to the step. The highly doped emitter has been selected for improving contact quality and maximizing $\mathrm{Ag}$-crystallite creation thanks to the presence of a high amount of inactive phosphorous [15]. Although this emitter can limit efficiency values, the main experimental objective is to assure a high quality contact, and to further analyze the evolution of the contact and the rest of cell parameters during the extended contact co-firing.

The effect of using an extended co-firing instead of the usual standard recipe is studied. Three groups of wafers receive the different time-temperature co-firing profiles represented in Fig. 2.The first recipe corresponds to the standard co-firing, consisting of a first $40 \mathrm{~s}$ step, with temperatures between 475 and $600{ }^{\circ} \mathrm{C}$, followed by a temperature peak of $10 \mathrm{~s}$. The second and third recipe correspond to extended co-firing 1 and 2, respectively, and they consist of a standard co-firing followed by one or two annealing steps at $500-600{ }^{\circ} \mathrm{C}$ during $50 \mathrm{~s}$. Maximum annealing time (50 s) is technically limited by belt furnace characteristics that prevent furnace over-heating. In terms of impurity behavior, simulations show that the beneficial effect caused by a longer annealing time effect can be similarly obtained by applying subsequent short annealing steps with very fast cooling ramps between them.

Firing set peak temperature of the three recipes is varied between 700 and $880{ }^{\circ} \mathrm{C}$ to optimize the extended versions of the co-firing while avoiding to shunt the emitter due to overfiring.
On the one hand, macroscopic characterization of the final cell is performed. Cell parameters are tested using an IV probe station and contact resistance of the front side is measured applying the Transfer Length Method (TLM) [16]. On the other hand, microscopic characterization of the contact is carried out using Scanning Electron Microscopy (SEM) in reference samples after a standard co-firing and an extended co-firing 1. Cross-sectional lamellae samples are previously prepared with in-situ Focused Ion Beam (FIB).

\section{RESULTS AND DISCUSSION}

\section{A. Cell parameters after different profile recipes}

Representative results obtained for cell parameters of reference samples using standard co-firing and extended co-firing 1 and 2 with temperature peak of $820{ }^{\circ} \mathrm{C}$ are shown in Table I.

It can be observed that implementing an annealing reduces cell efficiency by $-0.4 \%_{\text {abs }}$ and fill factor by $-0.7 \%_{\text {abs }}$. When the annealing is performed two times, higher reduction is observed (-1\% abs efficiency and $-4 \%_{\text {abs }}$ fill factor).

\section{B. Annealing effect on series resistance and fill factor}

Samples are fired using the three type of recipes shown in Fig. 2, varying in addition peak temperature between

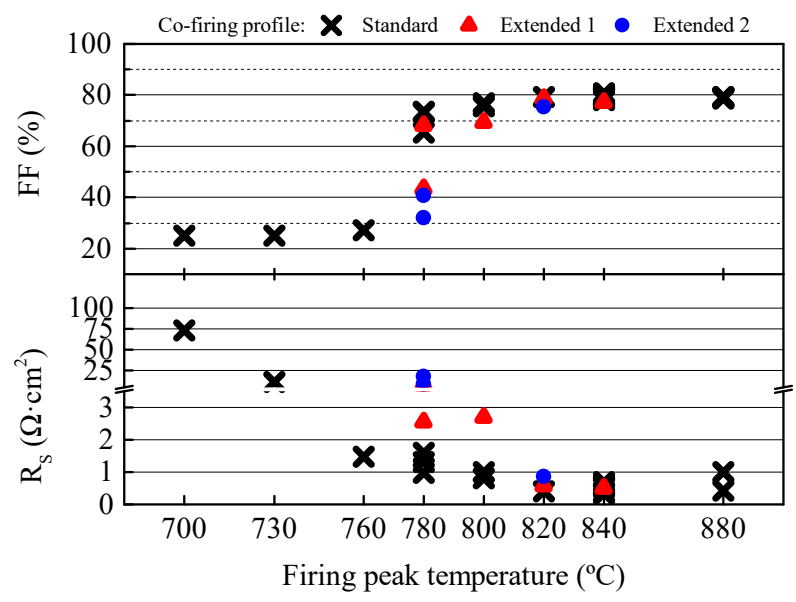

Fig. 3. Measured fill factor and fitted series resistance of cells using different co-firing temperature profiles varying firing peak temperature. 
700 and $880{ }^{\circ} \mathrm{C}$. Fig. 3 shows the dependence of measured solar cell fill factor and fitted series resistance on firing peak temperature, representing standard co-firing with black crosses, extended co-firing 1 with red triangles, and extended co-firing 2 with blue dots.

It can be observed that the optimum firing peak temperature for the standard co-firing is $840^{\circ} \mathrm{C}$, using our specific material and processes. Looking at the spike temperatures around the optimum one, series resistance of cells fabricated with the extended co-firing profiles are higher than those obtained with the standard co-firing. Consequently, fill factors using the extended co-firing profiles are lower than those obtained with the standard one. As open-circuit voltage has a mean value of $613 \pm 2 \mathrm{mV}$ without correlation with type of co-firing profile (standard or extended) or with spike temperature, fill factor decrease is then related to the series resistance increase. It is important to mention that in the case of highly-contaminated wafers, this open-circuit voltage has been experimentally observed to increase due to gettering of highly recombinant impurities (see the example in II, but this effect is not evident in this experiment because of the use of lowly contaminated material. In addition, the very highly doped emitter diffusion, selected for improving contact quality, can limit cell performance below the material potential.

Using the standard co-firing (black crosses), we observe series resistance increase and fill factor decrease when peak temperature decreases. This is likely due to the fact that temperature is not high enough to allow the metal paste totally etch the silicon nitride and create silver crystallites during co-firing [1]. After using the extended co-firing recipes 1 and 2 (red triangles and blue dots, respectively), series resistance increases and fill factor decreases when the peak temperature decreases, following the trend observed for the standard co-firing profile, but with worse results when more annealing steps are used. The higher series resistance after standard co-firing, the worse the deteriorating effect of the annealing. Annealing at $600{ }^{\circ} \mathrm{C}$ does not contribute to the silicon nitride etching nor the crystallite formation, as can be observed with a series resistance value that does not decrease after annealing. To explain the increased series resistance, the most likely reason is attributed to a growth in thickness of the glass layer appearing at the interface between the metal bulk and silicon [3]. Hypothetically, the worse the initial contact after the temperature spike, the faster the glass layer growth. In addition, a higher series resistance at spike temperatures below the optimum one $\left(840{ }^{\circ} \mathrm{C}\right)$ can also be attributed to an incomplete silicon nitride etching and silver crystallite formation [1].

Additionally, a reduction of the firing peak duration followed by an annealing was tested, with the objective of reducing the thickness of the formed glass layer. However, the metallic belt of the furnace has a thermal inertia that maintains the temperature, and then, in our experiments, solar cell parameters are not sensible to the firing peak duration reduction from 10 to 5 seconds.

\section{Annealing effect on specific contact resistance}

Specific contact resistance $\left(\rho_{\mathrm{c}}\right)$ has been measured by TLM after a standard co-firing temperature profile using the optimal firing temperature peak of $840{ }^{\circ} \mathrm{C}$ followed by a different number of annealing steps at $600{ }^{\circ} \mathrm{C}$ during $50 \mathrm{~s}$ each. Fig. 4 shows the results. Using this temperature peak, an optimum specific contact resistance of $0.8 \mathrm{~m} \Omega \cdot \mathrm{cm}^{2}$ has been measured that confirms an adequate initial silicon nitride etching and silver crystallite formation.

However, adding annealing steps after the standard cofiring increases $\rho_{\mathrm{c}}$, measuring a higher increase when the annealing step is repeated. This result is consistent with the increased series resistance reported in the previous section, and confirms that it is probably caused by the growth of the interfacial glass layer thickness during $600{ }^{\circ} \mathrm{C}$ annealing steps.

\section{Scanning Electron Microscopy after standard and extended co-firing}

Observed and reported in previous studies on current flow paths are: (1) direct contact between emitter and Ag-bulk via Ag crystallites or partially covered by a thin (up to a few nanometers) glass layer [17]-[20], and (2) contact through interfacial glass layer richly decorated with nano-Ag colloids [3], [19], [21]. A sample after standard co-firing using the optimal peak temperature of $840{ }^{\circ} \mathrm{C}$ and a sample after extended co-firing 1 are measured using Scanning Electron Microscopy (SEM). Cross section samples below the metal finger are prepared in-situ using FIB milling. Figs. 5a, 5b and $5 \mathrm{c}$ show the results. The contact fired using the standard firing corresponding to Fig. 5a shows an Ag-crystallite that presents direct contact between silicon and Ag-bulk (blue marked) allowing the direct current path.

After annealing (Figs. 5b and 5c), all the crystallites shown in the images are totally surrounded by a thicker glass layer ( $>100 \mathrm{~nm}$-thick) without presenting direct contact between Ag crystallite and Ag bulk and without an apparent possible nano-Ag colloids path. This glass layer redistribution around the crystallites, without presenting direct current paths -free of interfacial glass layer-, most probably causes the measured series resistance increase. A similar correlation of the SEM measured interfacial glass layer thickness with the increase of series resistance and contact resistance has been also observed in other studies [3], [22], [23]. One possible solution would be to tailor the composition of the paste to avoid the glass layer growth for supporting low temperature annealing steps below the firing temperature.

\section{E. Consequences for mc-Si degradation phenomena}

The findings presented above are not only important for cell parameters measured directly after cell processing. It is known from literature that mc-Si solar cells can degrade under illumination and slightly elevated temperature on a timescale of many hours and days (also called light and 


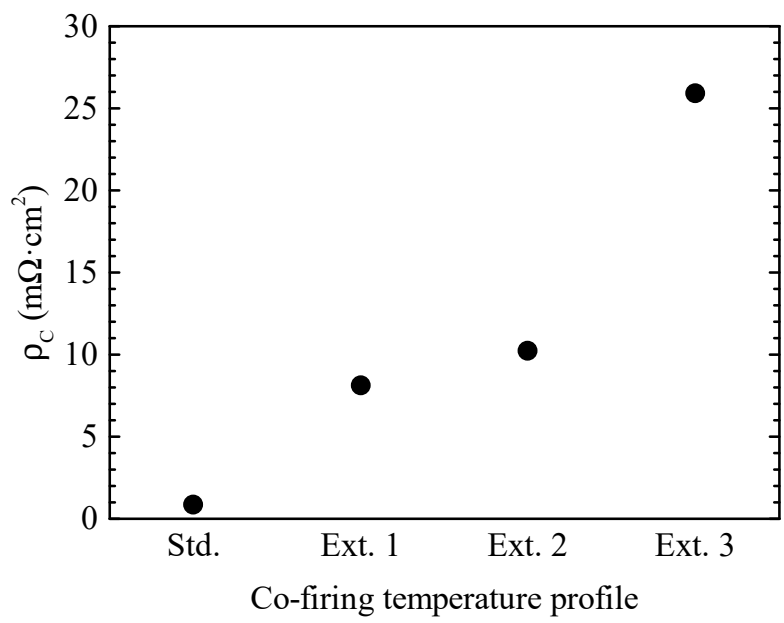

Fig. 4. Specific contact resistance $\left(\rho_{\mathrm{c}}\right)$ measured by Transfer Lenght Method (TLM) after standard co-firing (Std.), extended co-firing 1 (Ext. 1), extended co-firing 2 (Ext. 2), and extended co-firing 3 (Ext. 3), which corresponds to a standard co-firing followed by three annealing steps at $600{ }^{\circ} \mathrm{C}$ during 50 seconds. Peak of temperature is $840^{\circ} \mathrm{C}$ in all the recipes.

elevated temperature induced degradation, LeTID) [24], [25]. It is known that high temperature steps during cell processing are influencing the strength of this degradation, and that they can be minimized by an effective external gettering [26]. It could also be shown that the firing step has a strong influence on LeTID strength, and that it can be minimized by applying a co-firing step at lower temperature [27], [28]. Recently, it could be demonstrated that an additional second firing step at lower peak temperature can significantly reduce the LeTID strength, and it was pointed out that although LeTID can be reduced, cell efficiency (series resistance) might be affected by this second lower temperature firing step [29]. The reason for the possible negative impact on solar cell parameters is not given in [29], but based on our results presented above we think that a thickening of the glass layer might be the reason for this behavior.

\section{CONCLUSiOnS}

The effect of using extended contact co-firing temperature profiles on solar cell performance, in particular on contact formation quality, has been analyzed. Annealing steps after a standard co-firing step increase series resistance and consequently decrease fill factor for a range of peak temperatures tested. The lower the peak temperature, the higher the increase of series resistance during annealing. Specific contact resistance measurements using TLM show an increase of this parameter after the annealing steps as compared to the results after the optimal standard recipe. SEM images after standard and extended co-firing steps show a redistribution and thickening of the glass layer surrounding the Agcrystallites during the annealing at low temperature decreasing the possibility of a current path through direct contact of Agcrystallites with the Ag-bulk. This growth of the glass layer

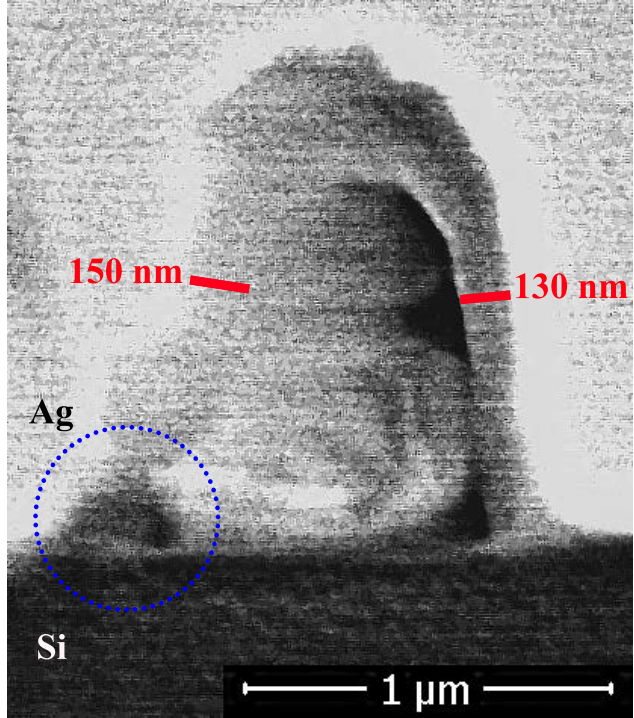

(a) After standard co-firing

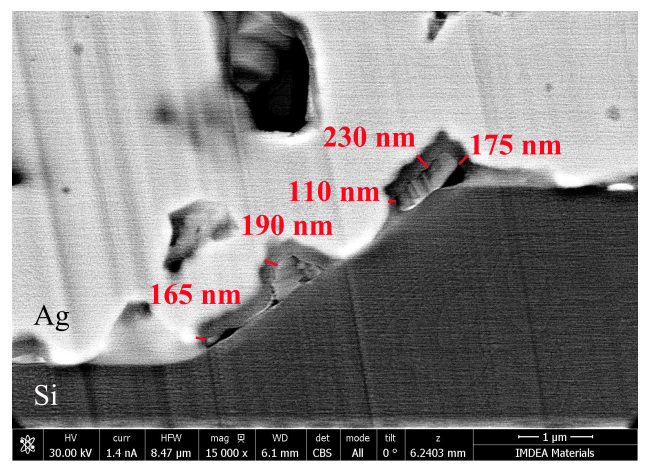

(b) After extended co-firing 1

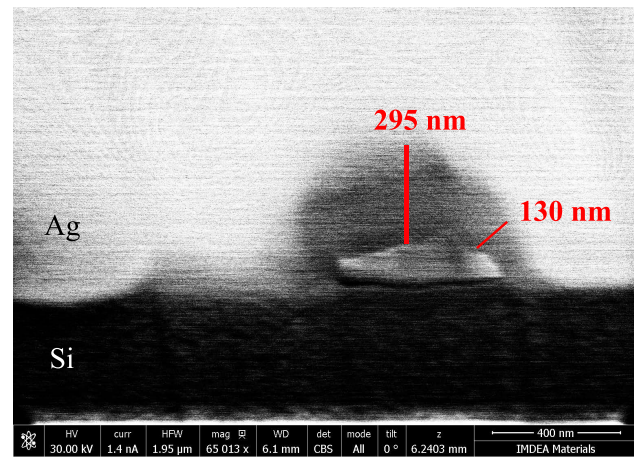

(c) After extended co-firing 1

Fig. 5. Cross-sectional SEM images of the contact after a standard co-firing and after a extended co-firing, with the optimum peak temperature of 840 ${ }^{\circ} \mathrm{C}$. Blue mark correspond to a direct current path present in the sample after standard co-firing.

can be related to the increase of series resistance and specific contact resistance measured. Degradation of series resistance during the spike temperature, when it is below the optimum one, can be also attributed to an incomplete silicon nitride etching and silver crystallite formation. The beneficial effects on emitter and bulk recombination using extended co-firing demonstrated in previous works require the development of the appropriate metallic screen-printing pastes supporting low 
temperature annealing steps without a significant glass layer thickening.

\section{ACKNOWLEDGMENT}

A. Peral gratefully acknowledges Dr. Miguel Castillo and Dr. Roberto Guzman for their assistance with FIB-SEM measurements at IMDEA Materials and Fellowship for Visiting Scientists Stays (EEBB-I-14-08268 and EEBB-I-15-09198) of the Programme for Training of Researchers of the Ministry of Economy and Competitiveness of Spain. This work has been partly funded by the Spanish Ministerio de Ciencia e Innovacin through TABACO project ENE2014-56069-C4-2-R project, and by Comunidad de Madrid through the MADRIDPV S2013/MAE-2780 project.

\section{REFERENCES}

[1] G. Schubert, "Thick film metallisation of crystalline silicon solar cells: Mechanisms, models and applications," Ph.D. dissertation, University of Konstanz, 2006

[2] M. M. Hilali, "Understanding and development of manufacturable screen-printed contacts on high sheet-resistance emitters for low-cost silicon solar cells," Ph.D. dissertation, Georgia Institute of Technology, 2005.

[3] S.-B. Cho, H.-S. Kim, and J.-Y. Huh, "Mechanism underlying the beneficial effect of forming gas annealing on screen-printed Ag contacts of crystalline Si solar cells," Acta Materialia, vol. 70, pp. 1-7, May 2014.

[4] V. R. Mehta, "Formation of screen-printed contacts on multicrystalline silicon (mc-Si) solar cells," Ph.D. dissertation, New Jersey Institute of Technology, 2010

[5] J.-F. Lelièvre, J. Hofstetter, A. Peral, I. Hoces, F. Recart, and C. del Cañizo, "Dissolution and gettering of iron during contact co-firing," Energy Procedia, vol. 8, pp. 257-262, 2011.

[6] A. Peral, J. F. Lelièvre, F. Recart, and C. del Cañizo, "Defect engineering during the contact co-firing step in an industrial belt furnace," physica status solidi (c), vol. 9, no. 10-11, pp. 2107-2110, Oct. 2012.

[7] B. Michl, J. Schön, W. Warta, and M. Schubert, "The Impact of Different Diffusion Temperature Profiles on Iron Concentrations and Carrier Lifetimes in Multicrystalline Silicon Wafers," IEEE Journal of Photovoltaics, vol. 3, no. 2, pp. 635-640, Apr. 2013.

[8] D. Macdonald, A. Cheung, and A. Cuevas, "Gettering and poisoning of silicon wafers by phosphorus diffused layers," in Photovoltaic Energy Conversion, 2003. Proceedings of 3rd World Conference on, vol. 2. IEEE, 2003, pp. 1336-1339.

[9] A. E. Morishige, H. S. Laine, J. Schön, A. Haarahiltunen, J. Hofstetter, C. del Cañizo, M. C. Schubert, H. Savin, and T. Buonassisi, "Building intuition of iron evolution during solar cell processing through analysis of different process models," Applied Physics A, vol. 120, no. 4, pp. 1357-1373, Jul. 2015.

[10] M. Rinio, A. Yodyunyong, S. Keipert-Colberg, Y. P. B. Mouafi, D. Borchert, and A. Montesdeoca-Santana, "Improvement of multicrystalline silicon solar cells by a low temperature anneal after emitter diffusion," Progress in Photovoltaics: Research and Applications, vol. 19 no. 2, pp. 165-169, Mar. 2011.

[11] J. Hofstetter, J.-F. Lelièvre, D. P. Fenning, M. I. Bertoni, T. Buonassisi, A. Luque, and C. Del Cañizo, "Enhanced iron gettering by short, optimized low-temperature annealing after phosphorus emitter diffusion for industrial silicon solar cell processing," Physica Status Solidi (c), vol. 8, no. 3, pp. 759-762, 2011.

[12] J. Schön, H. Habenicht, M. C. Schubert, and W. Warta, "Understanding the distribution of iron in multicrystalline silicon after emitter formation: Theoretical model and experiments," Journal of Applied Physics, vol 109, no. 6, p. 063717, 2011.

[13] A. Dastgheib-Shirazi, A. Peral, M. Steyer, J. Rinder, H. Wagner, and G. Hahn, "Dissolution of Electrically Inactive Phosphorus by Low Temperature Annealing," Energy Procedia, vol. 77, pp. 286-290, Aug. 2015.

[14] I. B. Cooper, A. Ebong, J. S. Renshaw, R. Reedy, M. Al-Jassim, and A. Rohatgi, "Understanding and use of IR belt furnace for rapid thermal firing of screen-printed contacts to Si solar cells," Electron Device Letters, IEEE, vol. 31, no. 5, pp. 461-463, 2010.
[15] E. Cabrera, S. Olibet, D. Rudolph, P. E. Vullum, R. Kopecek, D. Reinke, C. Herzog, D. Schwaderer, and G. Schubert, "Impact of excess phosphorus doping and $\mathrm{Si}$ crystalline defects on $\mathrm{Ag}$ crystallite nucleation and growth in silver screen-printed $\mathrm{Si}$ solar cells: Impact of emitter and crystal defects on Si solar cell Ag metallization," Progress in Photovoltaics: Research and Applications, vol. 23, no. 3, pp. 367-375, Mar. 2015.

[16] D. L. Meier and D. K. Schroder, "Contact resistance: Its measurement and relative importance to power loss in a solar cell," IEEE Transactions on Electron Devices, vol. 31, no. 5, pp. 647-653, May 1984.

[17] C. Ballif, D. M. Huljić, G. Willeke, and A. Hessler-Wyser, "Silver thickfilm contacts on highly doped n-type silicon emitters: Structural and electronic properties of the interface," Applied Physics Letters, vol. 82, no. 12 , p. $1878,2003$.

[18] S. Kontermann, R. Preu, and G. Willeke, "Calculating the specific contact resistance from the nanostructure at the interface of silver thick film contacts on n-type silicon," Applied Physics Letters, vol. 99, no. 11, p. $111905,2011$.

[19] P. Kumar, B. Willsch, M. Dürrschnabel, Z. Aabdin, R. Hoenig, N. Peranio, F. Clement, D. Biro, and O. Eibl, "Combined Microstructural and Electrical Characterization of Metallization Layers in Industrial Solar Cells," Energy Procedia, vol. 67, pp. 31-42, Apr. 2015

[20] R. Hoenig, M. Duerrschnabel, W. van Mierlo, Z. Aabdin, J. Bernhard, J. Biskupek, O. Eibl, U. Kaiser, J. Wilde, F. Clement, and D. Biro, "The Nature of Screen Printed Front Side Silver Contacts - Results of the Project MikroSol," Energy Procedia, vol. 43, pp. 27-36, 2013.

[21] Z. G. Li, L. Liang, and L. K. Cheng, "Electron microscopy study of front-side Ag contact in crystalline Si solar cells," Journal of Applied Physics, vol. 105, no. 6, p. 066102, 2009.

[22] M. M. Hilali, S. Sridharan, C. Khadilkar, A. Shaikh, A. Rohatgi, and S. Kim, "Effect of glass frit chemistry on the physical and electrical properties of thick-film Ag contacts for silicon solar cells," Journal of Electronic Materials, vol. 35, no. 11, pp. 2041-2047, Nov. 2006.

[23] S. Kontermann, M. Hörteis, M. Kasemann, A. Grohe, R. Preu, E. Pink, and T. Trupke, "Physical understanding of the behavior of silver thickfilm contacts on n-type silicon under annealing conditions," Solar Energy Materials and Solar Cells, vol. 93, no. 9, pp. 1630-1635, Sep. 2009.

[24] Ramspeck, K., Zimmermann, S., Nagel, H., Metz, A., Gassenbauer, Y., Birkmann, B., and Seidl, A., "Light Induced Degradation of Rear Passivated mc-Si Solar Cells," Proc. 27th EUPVSEC Frankfurt, pp. 861$865,2012$.

[25] F. Kersten, P. Engelhart, H.-C. Ploigt, A. Stekolnikov, T. Lindner, F. Stenzel, M. Bartzsch, A. Szpeth, K. Petter, J. Heitmann, and J. W. Müller, "Degradation of multicrystalline silicon solar cells and modules after illumination at elevated temperature," Solar Energy Materials and Solar Cells, vol. 142, pp. 83-86, Nov. 2015.

[26] A. Zuschlag, D. Skorka, and G. Hahn, "Degradation and regeneration in mc-Si after different gettering steps," Progress in Photovoltaics: Research and Applications, vol. submitted.

[27] D. Bredemeier, D. Walter, S. Herlufsen, and J. Schmidt, "Lifetime degradation and regeneration in multicrystalline silicon under illumination at elevated temperature," AIP Advances, vol. 6, no. 3, p. 035119, Mar. 2016.

[28] K. Nakayashiki, J. Hofstetter, A. E. Morishige, T.-T. A. Li, D. B. Needleman, M. A. Jensen, and T. Buonassisi, "Engineering Solutions and Root-Cause Analysis for Light-Induced Degradation in p-Type Multicrystalline Silicon PERC Modules," IEEE Journal of Photovoltaics, vol. 6, no. 4, pp. 860-868, Jul. 2016.

[29] C. E. Chan, D. N. R. Payne, B. J. Hallam, M. D. Abbott, T. H. Fung, A. M. Wenham, and S. R. Wenham, "Rapid stabilization of highperformance multi-crystalline p-type silicon PERC cells," Proc. 43rd IEEE PVSC Portland, p. pages not yet known, 2016.

Authors photographs and biographies not available at the time of publication. 